\title{
Exploration on the Construction of Innovation Base in Colleges with Industry Characteristics
}

\author{
Yong-gang YANG ${ }^{1}$, Gai-mei ZHANG ${ }^{1}$, Yue-heng DING ${ }^{1}$, Jia-wei ZHAO ${ }^{1}$ \\ Rui-na WANG ${ }^{1}$ and Qiao-zhuo $\mathrm{GAO}^{2, *}$ \\ ${ }^{1}$ Beijing Institute of Graphic Communication, Beijing, China \\ ${ }^{2}$ The Emerald City Branch of Beijing Primary School, Beijing, China \\ ${ }^{*}$ Corresponding Author
}

Keywords: Industry Characteristics; Innovation Base; Printing and Packaging.

\begin{abstract}
The construction of innovation base is an important link in the teaching quality and teaching reform project of higher education. Combining with the construction of innovation base in the university of industry characteristics, the paper introduces and analyzes the university of industry characteristics-Beijing Printing College and the construction idea, management mode and construction achievements of its campus innovation practice base, as well as the further work that the university of industry characteristics do for students during the process of constructing innovative training in order to meet the need for entrepreneurship education.
\end{abstract}

\section{Introduction}

In order to deepen the reform of universities, innovate teaching ideas, training modes and management mechanisms, cultivate students' practical ability, creative spirit and team cooperation consciousness, improve the quality of talent development training in universities, in November 2011, the Beijing Municipal Education Commission released the document entitled "The Notice on developing an Innovative practice base in Universities in Beijing" (Beijing Education Letter [2011] 702), the universities in Beijing actively develop the construction of the innovative practice base. Beijing Institute of Graphic Communication insists on the school-running tenet of "establishing schools by quality, strengthening schools by talents, driving innovations by creation". It effectively integrates the superior resources both inside and outside the school, based on the characteristic dominant specialties such as printing engineering, packaging engineering and mechanical engineering, devoted to develop innovative, comprehensive and applied high-level engineering talents and focus on enhancing and strengthening students' practical ability, cooperation ability, innovation abilities and engineering qualities [1]. The innovative practice base in the universities was built on the basis of the comprehensive training center of printing engineering. It provides the hardware conditions such as space, equipment for students' subject competition and innovative activities, at the same time it also equipped with guidance teachers.

\section{The Idea of Developing Innovative Talents}

The base insists on the principle of "facing industry, paying attention to characteristics, highlighting innovation, project-driven, open sharing and independent management" and focus on the goal of "developing printing and packaging engineering innovative talents", it can give a well environment and atmosphere which will develop students' independent innovation abilities and innovative consciousness, help the printing and publishing industry to cultivate high-level talents with comprehensive ability and innovative spirit, and improve the quality of personnel training by exploring the effective mode of innovative talents training in universities, building a platform for students' independent practice, and constructing a long-term mechanism for students' independent practice.

Facing the Industry and Paying Attention to Characteristics. Printing engineering and packaging engineering are specialties which facing the modern printing, packaging and related 
industries, they actively adapt to the needs of national economic construction and social development, train high-level specialized talents who have printing, packaging engineering professional comprehensive quality and innovative spirit of the application. Therefore, based on Beijing, facing the industry, relying on the base to cultivate high-level innovative and professional application-oriented talents to meet the needs of cultural and creative development, promote the development of digital printing, packaging printing and personalized printing, and promote the progress of printing and reproduction technology in our country [2].

Highlight Innovation and Project Driven. There are many practical and innovative activities of students supported by the base, including subject competitions, entrepreneurship projects, research projects, investigation and research, scientific and technological papers, qualification certification and participation in teachers' scientific research. Teachers should gradually step into the background to provide more support and guidance and we should drive students' enthusiasm by projects. The base takes the discipline competition as the lead, and relying on various kinds of projects, implements project-driven teaching. It explores a scientific, effective and simple way for students to improve their practical ability, teamwork ability and innovation ability.

Open Sharing and Self Management. Under the condition of safety, supervision and monitoring mechanism which can be guaranteed, we can achieve the comprehensive opening of the innovation practice base. On the basis of guaranteeing students' basic practical teaching, we should organize students to participate in various innovative competitions in printing and packaging, so that students can carry out various forms of innovative and competitive activities, and we will allocate a certain amount of funds from the operating funds for students' activities and rewards [3].

The practice base actively explores the new training mode of innovative talents with goals, space, teams, projects, guidance and financial support by improving the space for independent creativity, improving supporting facilities and increasing the financial support for projects, we do this to support college students to carry out independent research, creation and entrepreneurship practice.

\section{The Management Mode}

Two Levels of Management and Overall Layout. The base is managed by two levels, the direct leadership is the vice-president of teaching in the school, and the Academic Affairs Department of the college is responsible for business guidance. The director of the base is responsible for the overall development and construction of the base planning, researching and solving major problems in the development, formulating policies and guiding the daily management and operation of the base. We form a support mechanism which has five layers: school-level leadership --- Department' Synergy --- teachers' supporting --- student's participation --- expert' guidance. This guarantees the operation feasibility, long-term effectiveness of the base.

Project Driven, Multi-mode Guidance. The base takes the discipline competition as the lead, and depends on various kinds of projects, implements project-driven teaching. It explores a scientific, effective and simple way for students to improve their practical ability, teamwork ability and innovation ability. According to the actual characteristics of different disciplines and specialties, the base has established and implemented flexible and diverse operation modes, including scientific and technological innovation competition mode, entrepreneurship training mode and scientific research mode.

Students' Self-management and Improve the Utilization Rate. Various forms of students' management mode play an important role in the daily operation and maintenance of the base. In order to carry out all kinds of students' innovative activities smoothly, a scientific and efficient management system is needed in the innovation practice base of university students, in order to construct a network between the teachers and the students, and to ensure the daily operation of the base by rules and regulations, so as to realize top-down management. In order to maximize the use efficiency of the base, various student associations are mainly responsible for the daily management of the base, organizing subject knowledge competitions and publicity, mobilization of innovative practical activities. Students' independent management can effectively stimulate students' interest and enthusiasm in participating in innovative practice activities, expand the benefits, and enhance 
students' independent learning ability, practical ability and innovative ability [4].

\section{The Results of the Construction of the Practice Base}

Highlight the Construction Advantages of "Cross-integration of Printing and Packaging Disciplines", and Constructing a Practical Teaching System of "Engineering, Stimulating Innovation and Highlighting Capabilities". Strengthen the establishment of innovative systems in professional courses and improve "innovative" and "design" "Comprehensive" experimental proportions and levels, explore and build a number of more innovative and engineering technology projects. The proportion of college students' science and technology innovation activities in the teaching plan will be added to ensure the smooth development of science and technology innovation activities. In the teaching, the emphasis is placed on the cultivation of students' scientific and technological innovation ability. The students' science and technology innovation activity mode are incorporated into the application education teaching link, and relevant courses are set up for university students to carry out scientific research activities, and innovative credits are set up to link scientific and technological innovation activities with graduation and degree. Increase the investment in funds, equipment, venues and other related hardware to improve the level of science and technology innovation projects for college students.

Introducing Incentive and Competition Mechanisms, Further Adopting a Teaching Model of Level-by-level Training, and Project-driven Improvement of Students' Initiative. Based on curriculum experiments, an experimental teaching system is constructed, and comprehensive tests, design experiments, and innovative experiments are gradually formed. Hierarchical and step-by-step classification teaching mode, to cultivate students' independent, collaborative and research-based three-dimensional innovation abilities [5]. Through multi-level, modular practice teaching system and open management, it provides favorable conditions for the needs of different students to achieve scientific research and innovation, and the implementation of national-level entrepreneurial innovation training programs.

Establishing a Sound Institutionalization and Projectization, and Strengthening Students' Self-management Ability and Teamwork Ability. Encourage students to communicate and interact through the establishment of incentive mechanisms and project management systems. The addition of some scientific research projects that are closely related to modern high-tech and closely related to theoretical courses and professional training will help improve the level of scientific research and engineering and engineering practice. Taking the excellent works and projects of the base as a model and expanding into more professional courses, more students can get the opportunity to participate in science and technology projects of their own interest and realize their teaching in accordance with their aptitude.

Strengthening School-enterprise Cooperation and Further Expanding the Demonstration Effect and Radiation Effect of the Base. If the work of innovation practice base innovation practice base is long-term, the role of college students in practical ability, innovation consciousness and innovation ability will become increasingly prominent. During the operation process, we should build and summarize, grasp and accumulate in parallel with the publicity, strengthen the integration and promotion of the results of the construction of the innovation base, pay attention to the demonstration effect and the role of radiation, and make full use of this platform to bring more students' autonomy and innovation. Sexual well-being is the essential work and core task of colleges and universities.

Strengthening International Exchanges and Raising the Level of Internationalization. Accelerate the introduction of international faculty. In recent years, many foreign teachers have been employed by the college. They are mainly from the United States, Canada, the United Kingdom and other universities. On this basis, further increase the introduction; continue to implement international printing and packaging engineering. The curriculum system actively adopts an open practice teaching mode and a personalized practical teaching method to provide students with an internationalized vision of design practice concepts, methods, and cutting-edge information. In conjunction with the existing cooperation projects with the United States, the United Kingdom, 
Germany, Australia, Canada, Japan and other brothers and universities, the school will further expand the inter-school cooperation with foreign universities, and the two sides regularly send teachers to conduct international research in the form of academic seminars and academic visits. Exchange and exchange students to conduct international practical teaching activities in the form of regular internships and summer camps [6]. Encourage students to participate in various international science and technology competitions and expand the international influence of the center. In combination with the engineering excellence program and engineering certification, we will gradually achieve international standards and take the international road.

\section{Summary and Outlook}

After years of construction, our school's printing and packaging engineering innovation practice base has a new innovative practice teaching concept, a scientific practice teaching platform, a high level of practical teaching team, advanced equipment and safe environmental conditions, and efficient operation mechanism. And the standardized management system, carried out a wealth of innovative practice activities, formed a remarkable innovation practice teaching results and distinctive features. If the work of the innovation practice base is long-term construction and constantly thinks, summarizes and perfects, the role of college students in practical ability, innovation consciousness and innovation ability will play a huge role. In the future, we need to continue to focus on the role of demonstration and radiation, and make better use of this platform to lay the foundation for more students' autonomy and innovation.

\section{References}

[1] Chu Hanfang, Li Feng. Study and practice on management model and operating mechanism of experimental teaching demonstration center in colleges [J], Laboratory Science, 2010 (6): 139-141.

[2] Ren Jia, Wangjie, Liang Yong. Analysis and discussion on construction of innovation practice base of colleges and universities in Beijing [J], Experimental Technology and Management, 2014 (8): $222-224$.

[3] Meng Qingfan, Lu Jiahui, Meng Wei, et al. Study and practice about management system and operational mechanism of the exquisite experimental teaching laboratory [J], Experimental Technology and Management, 2006 (9): 1-4.

[4] Zhang Yongqin. Discussion on the research direction on the construction of innovation and entrepreneurship base in Chinese Universities [J], Comparative Study of Cultural innovation, 2018 (8): 114-118.

[5] Wang Jie. Analysis of focal points and difficulties of the campus innovation practice base construction [J], Research and Exploration in Laboratory, 2015 (4): 161-164.

[6] Xin Hongtao, Fan Xianwen,Wang Weiyi. The current situation, problems and direction of the research on the construction of innovation and entrepreneurship base in our country's university [J], Education for Chinese After-school, 2017 (12): 181-182. 